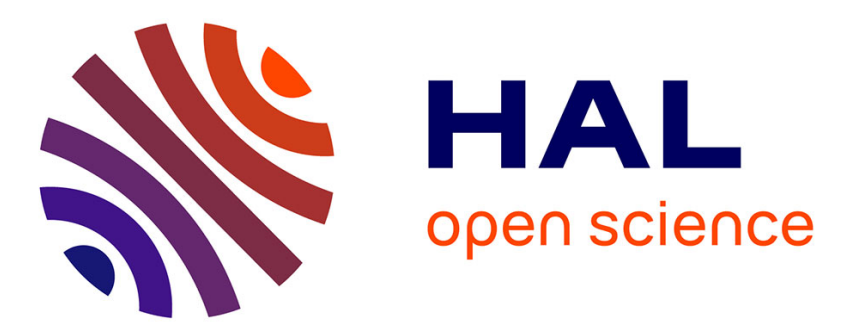

\title{
Fine analysis of interaction mechanism of bioactive glass surface after soaking in SBF solution AFM and ICP-OES investigations
}

\author{
N. Rocton, H. Oudadesse, B. Lefeuvre, H. Peisker, K. Rbii
}

\section{> To cite this version:}

N. Rocton, H. Oudadesse, B. Lefeuvre, H. Peisker, K. Rbii. Fine analysis of interaction mechanism of bioactive glass surface after soaking in SBF solution AFM and ICP-OES investigations. Applied Surface Science, 2020, 505, pp.144076. 10.1016/j.apsusc.2019.144076 hal-02472928

\section{HAL Id: hal-02472928 \\ https://hal-univ-rennes1.archives-ouvertes.fr/hal-02472928}

Submitted on 11 Feb 2020

HAL is a multi-disciplinary open access archive for the deposit and dissemination of scientific research documents, whether they are published or not. The documents may come from teaching and research institutions in France or abroad, or from public or private research centers.
L'archive ouverte pluridisciplinaire HAL, est destinée au dépôt et à la diffusion de documents scientifiques de niveau recherche, publiés ou non, émanant des établissements d'enseignement et de recherche français ou étrangers, des laboratoires publics ou privés. 
Fine analysis of interaction mechanism of bioactive glass surface after soaking in SBF solution: AFM and ICP-OES investigations

\author{
Nicolas Rocton ${ }^{\text {a }}$, Hassane Oudadesse ${ }^{\text {a }}$, Berfctrand Lefeuvre ${ }^{\text {a }}$, Henrik Peisker ${ }^{b}$, Khalid Rbii ${ }^{b}$ \\ aUniv Rennes, CNRS, ISCR-UMR 6226, F-35000 Rennes, France \\ bNanosurf GmbH , Rheinstrasse 5, 63225 Langen, Germany
}

Corresponding author: Prof. Dr. Hassane Oudadesse

E-mail: hassane.oudadesse@univ-rennes1.fr

Abstract

Bioactive glasses have the physical characteristics enabling them to be used in bone tissue engineering applications. However, the exact mechanism of the interactions between the glass surface and environment leading to the transition from the vitreous phase to the crystalline phase remains a subject of study. This work focuses on the growth of a calcium phosphate layer on the surface of the glass after immersion in a mineral solution, which mimics the mineral phase of human blood. The investigations use the Inductively Coupled Plasma and the Atomic Force Microscopy to establish the kinetic of crystallization, the kinetic of chemical reactivity and the surface transformations such as structure, texture and morphology of the bioactive glass. Obtained results show the progressive formation of a hydroxyapatite layer within 2 weeks. This crystal which is that of the bone belongs to the crystallographic structure within space group of $\mathrm{P} 6_{3 / \mathrm{m}}$. In addition, results show a decrease of the gradient of thickness which varies according to the immersion time from $7.5 \mu \mathrm{m}$ to $2.8 \mu \mathrm{m}$ and an increase of the homogeneity of the surface visible by the lowering of the gradient in the phase measurement from $60 \AA$ to $15 \AA$. 
Keywords: Bioactive glass, Surface behaviour, Hydroxyapatite, Bioactivity, Topography, Phases

\section{Introduction}

In the field of biomedical research, many different compositions were studied for their biocompatible properties and their actions within the body. Bioactive glass in the $\mathrm{SiO}_{2}-\mathrm{Na}_{2} \mathrm{O}-$ CaO- $\mathrm{P}_{2} \mathrm{O}_{5}$ system has been widely studied and their utility in the bone restoration area has been accepted [1-5]. Since their invention [6-8], synthetic biomaterials have been considered a good option for replacing biological bone grafts. Indeed, nowadays, calcium phosphate, calcium carbonate and bioactive glasses are used as biomaterials in orthopaedic surgery. They present the advantages of being available in unlimited quantity, offering a more adaptable option outside of heterografts and xenografts and completely avoiding disease transmission. In addition, recent studies show the possibility of further benefit brought by these materials. They may have other advantages such as the functionalization of their surface for the transport of molecules [9] of biological interest and activates biological reactions useful for the restoration of bone tissue such as cell differentiation [10], osteogenesis and angiogenesis [11]. All these characteristics must be investigated during the engineering of new biomaterials. In fact, bioactivity, reaction kinetics and physicochemical analysis are essential in order to obtain data on the evolution of these materials over time. They help understanding physicochemical mechanisms responsible for surface transformations once in contact with the physiological environment.

Nevertheless, the evolution over time of the biomaterials and the characteristics of the crystallization steps remains a topic of the current study. Atomic Force Microscope (AFM) [12] 
coupled with Inductively Coupled Plasma-Optical Emission Spectroscopy (ICP-OES) enable us to analyse the surface behaviour at the nano/micro scale and its growth over the time of soaking. Before that, crystalline structure and functional groups have had to be highlighted. These analyses will follow the crystallographic structure evolutions and functional groups formation after contact with SBF. X-ray Diffraction (XRD) and Fourier Transformation InfraRed (FTIR) techniques have been used. Complementarities between employed techniques such as XRD, FTIR, ICP-OES and AFM give a full range of information pertaining to the surface transformations from amorphous system to a calcium phosphate which is the mineral part of the mature bone. The hydroxyapatite crystal (HA) with chemical formula $\mathrm{Ca}_{10}\left(\mathrm{PO}_{4}\right)_{6}(\mathrm{OH})_{2}$ layer is similar to the crystal composing human bones.

Analysis by phase imaging and chemical mapping used in this study can be used in the characterisation of inorganic as well as organic compounds and translate into a visible difference between each element $[13,14]$. In this study, this mechanic will be used to characterize the transformation of the surface of the materials from glass to mature bone crystals. The two main characteristics tracked have been the roughness and the homogeneity of the surface. Roughness was measured using the gradient of the higher and lower part of the surface. Homogeneity was tracked by measuring vibrations of the AFM probe on the different surfaces, the change in reaction indicates a difference in the materials rugosity. In addition, measurements of layer thickness formed were made on the same samples as those used for roughness and homogeneity measurements in this work. Obtained results allow for a study of the transformation kinetics through the different phases of the crystallisation.

This study focuses on the synthesis of glass in the system $\mathrm{SiO}_{2}-\mathrm{Na}_{2} \mathrm{O}-\mathrm{CaO}-\mathrm{P}_{2} \mathrm{O}_{5}$ using the melting and quenching pathway. The chemical composition of the studied glass is $46 \% \mathrm{SiO}_{2}$ $24 \% \mathrm{CaO}-24 \% \mathrm{Na}_{2} 0-6 \% \mathrm{P}_{2} \mathrm{O}_{5}$ called $46 \mathrm{~S} 6$. It has been the subject of further studies within the laboratory $[15,16]$ and present a high potential for applications on the biomedical field [17-19]. 
The synthesis and characterization of the 46S6 will be further discussed in this study. Such discussion will explore the different stages of development of the HA layer after immersion in a Simulated Body Fluid (SBF) for three different durations.

\section{Material and Methods}

\subsection{Preparation of bioactive glass}

Sodium metasilicate $\left(\mathrm{Na}_{2} \mathrm{SiO}_{3}: 42.06 \mathbf{w t} \%\right)$, calcium metasilicate $\left(\mathrm{CaSiO}_{3}: 49.51 \mathbf{w t} \%\right)$ and sodium metaphosphate $\left(\mathrm{Na}_{3} \mathrm{P}_{3} \mathrm{O}_{9}: \mathbf{8 . 4 3} \mathbf{w t} \%\right)$ have been the initial products that were used to form the oxides $\mathrm{SiO}_{2} ; \mathrm{CaO}, \mathrm{Na}_{2} \mathrm{O}$ and $\mathrm{P}_{2} \mathrm{O}_{5}$ and obtain the desired composition of $46 \mathrm{wt} \% \mathrm{SiO}_{2}$, $24 \mathrm{wt} \% \mathrm{CaO}, 24 \mathrm{wt} \% \mathrm{Na}_{2} \mathrm{O}$ and $6 \mathrm{wt} \% \mathrm{P}_{2} \mathrm{O}_{5}$. Initial products have been weighed according to the quantity of glass required and mixed in a polyethylene bottle for 2 hours in a planetary mixer. Origin and purity of these chemicals are presented in table 1.

Table 1. Origin and purity of products for the melting process.

\begin{tabular}{ccc}
\hline Chemical Name & Source & Mole fraction purity ${ }^{\text {a }}$ \\
\hline Sodium metasilicate $\left(\mathbf{N a}_{2} \mathbf{S i O}_{3}\right)$ & Fisher chemical & $\geq 0.97$ \\
Sodium metaphosphate & Alfa Aesar & 0.95 \\
$\left(\mathbf{N a}_{3} \mathbf{P}_{3} \mathbf{O}_{9}\right)$ & Alfa Aesar & $\geq 0.97$ \\
Calcium metasilicate $\left(\mathbf{C a S i O}_{3}\right)$ & \\
${ }^{\text {a Purity of these elements has been controlled but elements have not been purified again. }}$
\end{tabular}

The mixed powder was melted in platinum crucibles because of its melting temperature of 1786 ${ }^{\circ} \mathrm{C}$, it avoids metal releases or eventual contaminations. It was placed in an electric furnace. The first rise of temperatures rate was $10^{\circ} \mathrm{C} \mathrm{min}^{-1}$ from 20 to $900{ }^{\circ} \mathrm{C}$ for a duration of one hour 
corresponding to a decarbonization process in order to separate the different oxides. During this phase, following reactions took place:

$$
\begin{gathered}
\mathrm{CaSiO}_{3} \rightarrow \mathrm{CaO}+\mathrm{SiO}_{2} \\
\mathrm{Na}_{2} \mathrm{SiO}_{3} \rightarrow \mathrm{Na}_{2} \mathrm{O}+\mathrm{SiO}_{2} \\
2 \mathrm{Na}_{3} \mathrm{P}_{3} \mathrm{O}_{9} \rightarrow 3 \mathrm{Na}_{2} \mathrm{O}+3 \mathrm{P}_{2} \mathrm{O}_{5}
\end{gathered}
$$

This period is followed by a new rise of temperature at $20^{\circ} \mathrm{C} \mathrm{min}-1$ until $1350{ }^{\circ} \mathrm{C}$ corresponding to our glass melting temperature. The melting phase consists of stabilization of the temperature at $1350{ }^{\circ} \mathrm{C}$ for three hours. The thermal elaboration process is described in figure 1.

After the melting phase, the sample was air quenched and transferred to a preheated cylindric brass mould, annealed at $\mathrm{Tg}=540 \pm 20{ }^{\circ} \mathrm{C}$ for 4 more hours to stabilize the glass in order to reduce physical tension due to the brutal loss of temperature during the air quenching.

\subsection{Formatting the sample}

Obtained cylinders of glasses have been put in wax. Following the waxing, each sample was polished in a moist environment so that only one side of the bioactive glass may be in contact with the physiological fluid during in vitro tests. In this way, the contact surface of the bioactive glass was identical for all samples. This polishing with silicon carbide paper (grain 2400) also removes the surface layer that may have been polluted. At the end of this operation, samples were rinsed using, alcohol and distilled water. Samples were shaped as small cylinders with a diameter of $13 \mathrm{~mm}$ for a high of $8 \mathrm{~mm}$ as shown in figure 2 .

\subsection{Physicochemical characterization techniques of elaborated glass}

\subsubsection{Thermal analysis.}


The glass thermal characteristics have been recorded by using Differential Scanning Calorimetry (DSC). Thermal characteristics measurements were carried out using a Setaram Labsys 1600TG-DTA/DSC thermal analyser under $\mathrm{N}_{2}$ gas atmosphere at $0.1 \mathrm{MPa}$ without precise pressure control.

\subsubsection{Structure and functional groups investigations by using XRD and FTIR.}

X-ray Diffraction (XRD) and Fourier transformed Infra-Red spectroscopy (FTIR) have been used to control structure and functional groups of the elaborated glass. The control of the amorphous nature and the potential displacements and/or new functional groups formation in these compounds were the main objectives of this characterization.

XRD patterns were recorded between $5^{\circ}$ and $90^{\circ}(2 \theta)$ by a PANalytical X'Pert PRO diffractometer with a precision of $0.026^{\circ}$ by steps and a count time of $40 \mathrm{~s}$ per step using $\mathrm{Cu}$ $\mathrm{K} \alpha$. Voltage was of $50 \mathrm{kV}$ and the current was $40 \mathrm{~mA}$ during analyses. Powdered samples were prepared for XRD analysis and back-loaded into steel sample holders.

For FTIR analysis, samples were embedded in $\mathrm{KBr}$ pellets and recorded by Bruker Equinox 55 spectrometer between $4000 \mathrm{~cm}^{-1}$ and $400 \mathrm{~cm}^{-1}$ in transmittance mode with a resolution of 2 $\mathrm{cm}^{-1}$. XRD and FTIR analyses were carried out at ambient temperature.

\subsubsection{Surface analysis by using AFM.}

Atomic Force Microscopy (AFM) has been used on the surface of the glass for three different immersion times corresponding to 2 weeks, 1 month and 2 months. The AFM operation mode used was phase imaging, sensitive to cantilever phase shifts due to changing interactions between the tip of the AFM cantilever and the surface. This enables topographical mapping of surfaces while simultaneously recording local material differences allowing surface structure and material domains to be directly compared. It is particularly useful in analysing polymers, 
composites, and surface coatings. Images have been obtained using a FlexV5+ Scanhead connected to a C3000 controller operating in Phase imaging mode in air with $158.614 \mathrm{kHz}$ vibration frequency and $1.5 \mathrm{~V}$ vibration amplitude. Image analysis was done using Mountain Maps Software.

\subsubsection{Thickness measurement of the formed hydroxyapatite layer}

The thickness of the deposited layer was measured using a digital microscope with 3D measurement technology (VHX-5000, KEYENCE) with a precision of $0.1 \mu \mathrm{m}$. The deposited layer was scratched with a blade until the vitreous surface appeared, then the thickness was measured at different points of the sample to calculate an average.

\subsection{In vitro assays.}

Soaking preparation for in vitro chemical reactivity has been carried out. Bioactive glass cylinders ( $8 \mathrm{~mm}$ of height and $13 \mathrm{~mm}$ of diameter) were placed in $8 \mathrm{~mL}$ of a previously prepared SBF solution. Only one surface of each cylinder has been in contact with SBF solution. Chemical composition of both SBF and human plasma are presented in table 2 [20]. These samples were placed in an incubator with a controlled agitation of 50 revs $\min ^{-1}$ and $37^{\circ} \mathrm{C}$ for fixed times. At the end of these times, each sample was rinsed thoroughly with distilled water and then dried at room temperature before shipping for AFM analysis. The SBF was also stored for analysis by ICP-OES. These analyses make it possible to highlight the ionic exchanges that took place between the surface of the immersed biomaterial and the synthetic physiological liquid. Concentrations of silicon $(\mathrm{Si})$, phosphorus $(\mathrm{P})$ and calcium $(\mathrm{Ca})$ in remaining SBF were measured for all different periods.

Table 2. Ionic concentrations of SBF and human blood plasma 


\begin{tabular}{lcccccccc}
\hline Ions (Mm) & $\mathbf{N a}^{+}$ & $\mathrm{K}^{+}$ & $\mathrm{Mg}_{2}{ }^{+}$ & $\mathbf{C a}_{2}{ }^{+}$ & $\mathbf{C l}^{-}$ & $\mathrm{HCO}_{3}{ }^{-}$ & $\mathbf{H P O}_{4}{ }^{2-}$ & $\mathbf{S O}_{4}{ }^{2-}$ \\
\hline SBF & 142.0 & 5.0 & 1.5 & 2.5 & 147.8 & 4.2 & 1.0 & 0.5 \\
Plasma & 142.0 & 5.0 & 1.5 & 2.5 & 103.0 & 27.0 & 1.0 & 0.5 \\
\hline
\end{tabular}

\section{Results and discussion}

3.1 Physicochemical characterization of bioactive glass.

\subsubsection{Thermal analysis of bioactive glass.}

DSC spectra show the presence of characteristic phase transition temperatures for a glass. The vitreous transition $T_{g}$, the crystallisation temperature $T_{c}$ and the melting temperature $T_{f}$ can be seen in figure 3. According to the literature [21], a glass must possess an amorphous structure and vitreous transition temperature; these characteristics confirm that the synthesized material is a glass and validate our chemical experimental protocol.

\subsubsection{Structure and functional grouping of studied bioactive glass.}

FTIR spectra for NBG powder presented in figure 4 show several vibration bands. The Si-OSi bending signal at $465 \mathrm{~cm}^{-1}$ and $1230 \mathrm{~cm}^{-1}$ in relation with phosphate groups vibrations at $1100 \mathrm{~cm}^{-1}$ and $585 \mathrm{~cm}^{-1}$ and finally the Ca presence confirmed by the vibration bands at 800 $\mathrm{cm}^{-1}$ assigned at Si-O-Ca with non-linking oxygen. The $3348 \mathrm{~cm}^{-1}$ band are due to $\mathrm{OH}^{-}$ anions, a group from the residual $\mathrm{H}_{2} \mathrm{O}$ adsorbed on the surface of NBG [22-26]. These results confirm the presence of all the typical groups.

XRD diffractograms presented in figure 5 shows signs of an increasing crystallization in the function of immersion time. This crystallization is due to the growth of a layer of the crystal 
similar to hydroxyapatite $\left(\mathrm{Ca}_{10}\left(\mathrm{PO}_{4}\right)_{6}(\mathrm{OH})_{2}\right)$ on the surface of the $46 \mathrm{~S} 6$ glass which was immersed in SBF. This information validates the bioactivity of the glass. These data also make it possible to set up an idea of crystallographic growth kinetics and different phases during the growth of the hydroxyapatite layer. The increase in immersion time leads to a growth in size and a decrease of the width at half height which can be observed on the two principal crystallisation peaks at $27^{\circ}$ and $34^{\circ}$. This is probably due to the structuring of the different elements into each crystal phase.

\subsubsection{Ionic exchanges and chemical reactivity of elaborated glass.}

The utilisation of the ICP-OES allows the measurement with high sensitivity and precise data (sensitivity of about $1 \mathrm{ppm}$ depending on the analysed matrix). It allows for the determination of ionic exchanges established between the glass and the SBF. Measurements have been carried out on the remaining SBF solution. Obtained results show variations of concentration of observed elements $\mathrm{Si}, \mathrm{Ca}$ and $\mathrm{P}$. Si is an indicator of glass dissolution when $\mathrm{Ca}$ and $\mathrm{P}$ are a indicators of calcium phosphate formation. While concentrations of $\mathrm{Ca}$ and $\mathrm{P}$ decrease with time, the Si concentration shows an increase due to the glass surface dissolution during the first 15 days that are followed by a significant stabilization. These results can be explained by the dissolution of the glass when it is in contact with SBF and the formation of a silica gel layer and finally the formation of a calcium phosphate crystal. This mechanism can be summarized in three successive phases: glass matrix dissolution followed by silica gel formation and then calcium phosphate precipitation. They are developed in five chemical stages as described in table 3. This result is in line with previous works [6]. Variation in the concentration of followed elements can be seen in figure 6 .

Table 3. Reaction stages of bioactive glass 


\section{Interaction mechanism between glass surface and SBF: Reaction stages}

Stage 1 Rapid exchange of cation such as $\mathrm{Ca}^{2+}$ with $\mathrm{H}^{+}$or $\mathrm{H}_{3} \mathrm{O}^{+}$from solution:

$$
\mathrm{Si}-\mathrm{O}-\mathrm{Ca}^{+}+\mathrm{H}_{3} \mathrm{O}^{+} \rightarrow \mathrm{Si}-\mathrm{OH}+\mathrm{Ca}^{2+}
$$

Stage 2 Loss of soluble silica in the form of $\mathrm{Si}(\mathrm{OH})_{4}$ to the solution resulting from breakage of Si-O-Si bonds and formation of Si-OH at the glass/solution interface.

$$
\mathrm{Si}-\mathrm{O}-\mathrm{Si}+\mathrm{H}_{2} \mathrm{O}=\mathrm{Si}-\mathrm{OH}+\mathrm{OH}-\mathrm{Si}
$$

Stage 3 Condensation and repolymerization of a $\mathrm{SiO}_{2}$ rich layer on the surface depleted in alkali and alkaline earth cations. $\mathrm{Si}-\mathrm{OH}+\mathrm{OH}-\mathrm{Si}=-\mathrm{Si}-\mathrm{O}-\mathrm{Si}-+\mathrm{H}_{2} \mathrm{O}$

Stage 4 Migration of $\mathrm{Ca}^{2+}$ and $\mathrm{PO}_{4}{ }^{3-}$ groups to the surface of forming $\mathrm{CaO}-\mathrm{PO}_{4}{ }^{3-}$ cluster on the top of the $\mathrm{SiO}_{2}$ rich layer, followed by the growth of the amorphous $\mathrm{CaP}$

Stage 5 Crystallization of amorphous $\mathrm{CaP}$ by incorporation of $\mathrm{OH}^{-}, \mathrm{CO}_{3}{ }^{2-}$ anions from solution to form a hydroxyl-carbonate apatite layer

\subsection{Surface analysis using AFM.}

Surface analyses of the samples that have been immersed for different periods were investigated by using AFM technique. Obtained results are presented in figures 7,8 and 9:2 conclusions can be drawn. The first one is the level gap and the second one is the homogeneity of the surface. 2 weeks after soaking, the topography results presented in figure 7 a show a variation of level with a maximum difference of $7.5 \mu \mathrm{m}$ in thickness, this difference decreases with the increase of immersion time. Topography of the one month after soaking presented in figure 8 a represents a smaller gap of $4 \mu \mathrm{m}$. Finally, in figure 9a, 2 months after soaking, the topography shows a gap of $2.8 \mu \mathrm{m}$. Results show a decrease of the surface roughness due to the transformation of the glass surface into a calcium phosphate crystal. 
Homogeneity of the surface is presented in the phase results. Homogeneity for the two weeks before soaking is presented in figure $7 \mathrm{~b}$, it shows significant variations between the high level and the low level, this gap is of about $60 \AA$. This difference shows material contrast put forth by a clear and distinct variance of the surface composition. This observed phenomenon shows a crystalline structure, which is most likely due to the HA layer formation. Longer periods of immersion in SBF shows more of a uniform material signal with sphere-like structures with only a few defects pointing to the material difference. Furthermore, the phase level gap decreases with the increase of immersion time. Respectively within a range of $40 \AA$ and $15 \AA$ for the one month after soaking in SBF as shown in figure $8 \mathrm{~b}$ and the two months after soaking as shown in figure 9b. Phases and topography overlay are available in figures $7 \mathrm{c}, 8 \mathrm{c}, 9 \mathrm{c}$ respectively for the two weeks, one month and two months after soaking in SBF solution.

\subsection{Thickness measurement results}

The measurements concerning the thickness of the hydroxyapatite layer formed show an increase in the thickness of the layer formed over time. The measurements made on the samples immersed two weeks has an average thickness of $193.5 \mu \mathrm{m}$, the samples immersed for 1 month an average thickness of $248.3 \mu \mathrm{m}$ and finally the samples immersed for 2 months an average thickness of $785.4 \mu \mathrm{m}$. An example of a 3D photography in the case of a sample immersed for 2 months is presented in figure 10 .

\section{Conclusion}

The biomaterials 46S6 presented in this work presents all the characteristics of bioactive glass. Physicochemical characterization highlighted its amorphous nature and vitreous transition temperature and its capacity to form chemical bonds and turn into a crystal has been recorded. 
Obtained results on the investigation of the surface state show the modification of the surface linked to the ionic exchanges between the materials and environment (SBF). These exchanges lead to changes in the surface state depending on the progress of the transformation of the vitreous matrix into the crystal.

The surface in contact with the liquid SBF has a progressive uniformity leading to a diminution of the roughness of its surface. This is observable using the AFM by the decrease of the level gap from $7.5 \mu \mathrm{m}$ for the two weeks after soaking sample to $4 \mu \mathrm{m}$ for the one month after soaking and finally to $2.8 \mu \mathrm{m}$ for the two months after soaking sample. Another result is the homogenization of the surface due to the progressive crystallisation. Measurements show variations in the gap of phase from $60 \AA$ for two weeks sample to a range of $40 \AA$ and $15 \AA$ for respectively one month and two months.

In addition, measurements of the thickness of the formed layer show an increase in thickness over time. It goes from $193.5 \mu \mathrm{m}$ for immersed samples for 2 weeks to $785.4 \mu \mathrm{m}$ for submerged samples for 2 months.

The objectives of this study were to enhance the comprehension of the chemical mechanism responsible for the interactions between glass and synthetic physiological liquid and then the surface behaviour of glass when it is in contact with physiological simulated solution. This knowledge allows for the development of better biomaterials, more adaptable in regard to the nature of the lesion or disease by understanding how the surface of the biomaterials undergo different modifications depending on the surrounding environment.

\section{Acknowledgments}

The authors gratefully acknowledge François Cheviré and Franck Tessier for the X-ray diffraction analyses and Marco Portalupi (Nanosurf GmbH, Rheinstrasse 5, 63225 Langen, 
Germany) for the AFM measurements. Authors would like to thank University of Rennes 1 and CNRS, France for supporting funding of this work. 


\section{References}

[1] Wers, E., Oudadesse, H., Lefeuvre, B., Bureau, B., Merdrignac-Conanec, O., 2014. Thermal investigations of Ti and Ag-doped bioactive glasses. Thermochimica Acta 580, 7984. https://doi.org/10.1016/j.tca.2014.02.001

[2] Wers, E., Oudadesse, H., Lefeuvre, B., Lucas-Girot, A., Rocherullé, J., Lebullenger, R., 2014. Excess entropy and thermal behavior of $\mathrm{Cu}$ - and Ti-doped bioactive glasses. Journal of Thermal Analysis and Calorimetry 117, 579-588. https://doi.org/10.1007/s10973-014$\underline{3731-5}$

[3] Wers, E., Oudadesse, H., Lefeuvre, B., Merdrignac-Conanec, O., Barroug, A., 2015. Evaluation of the kinetic and relaxation time of gentamicin sulfate released from hybrid biomaterial Bioglass-chitosan scaffolds. Applied Surface Science 353, 200-208. https://doi.org/10.1016/j.apsusc.2015.06.146

[4] Franchini, M., Lusvardi, G., Malavasi, G., Menabue, L., 2012. Gallium-containing phospho-silicate glasses: Synthesis and in vitro bioactivity. Materials Science and Engineering: C 32, 1401-1406. https://doi.org/10.1016/j.msec.2012.04.016

[5] Dietrich, E., Oudadesse, H., Lucas-Girot, A., Le Gal, Y., Jeanne, S., Cathelineau, G., 2008. Effects of $\mathrm{Mg}$ and $\mathrm{Zn}$ on the surface of doped melt-derived glass for biomaterials applications. Applied Surface Science 255, 391-395. https://doi.org/10.1016/j.apsusc.2008.06.094

[6] Hench, L.L., Splinter, R.J., Allen, W.C., Greenlee, T.K., 1971. Bonding mechanisms at the interface of ceramic prosthetic materials. Journal of Biomedical Materials Research 5, 117-141. https://doi.org/10.1002/jbm.820050611

[7] Hench, L.L., 1998. Biomaterials: a forecast for the future. Biomaterials 19, 14191423. https://doi.org/10.1016/S0142-9612(98)00133-1

[8] Hench, L.L., 2002. Third-Generation Biomedical Materials. Science 295, 1014-1017. https://doi.org/10.1126/science.1067404

[9] Xue, Y.; Zhang, Z.; Niu, W.; Chen, M.; Wang, M.; Guo, Y.; Mao, C.; Lin, C.; Lei, B. Enhanced Physiological Stability and Long-Term Toxicity/Biodegradation In Vitro/In Vivo of Monodispersed Glycerolphosphate-Functionalized Bioactive Glass Nanoparticles. Part. Part. Syst. Charact. 2019, 36 (4), 1800507. https://doi.org/10.1002/ppsc.201800507.

[10] Niu, W.; Guo, Y.; Xue, Y.; Chen, M.; Wang, M.; Cheng, W.; Lei, B. Monodisperse Branched Molybdenum-Based Bioactive Nanoparticles Significantly Promote Osteogenic Differentiation of Adipose-Derived Stem Cells. Part. Part. Syst. Charact. 2019, 36 (7), 1900105. https://doi.org/10.1002/ppsc.201900105.

[11] Tian, T.; Xie, W.; Gao, W.; Wang, G.; Zeng, L.; Miao, G.; Lei, B.; Lin, Z.; Chen, X. Micro-Nano Bioactive Glass Particles Incorporated Porous Scaffold for Promoting Osteogenesis and Angiogenesis in Vitro. Front. Chem. 2019, 7, 186. https://doi.org/10.3389/fchem.2019.00186. 
[12] Jalili, N., Laxminarayana, K., 2004. A review of atomic force microscopy imaging systems: application to molecular metrology and biological sciences. Mechatronics 14, $907-$ 945. https://doi.org/10.1016/j.mechatronics.2004.04.005

[13] Maver, U., Velnar, T., Gaberšček, M., Planinšek, O., Finšgar, M., 2016. Recent progressive use of atomic force microscopy in biomedical applications. TrAC Trends in Analytical Chemistry 80, 96-111. https://doi.org/10.1016/j.trac.2016.03.014

[14] Rao, S., Costa, K.D., 2014. Atomic Force Microscopy (AFM) in biomedical research, in: Biomedical Imaging. Elsevier, pp. 41-64. https://doi.org/10.1533/9780857097477.1.41

[15] Rocton, N., Oudadesse, H., Lefeuvre, B., 2018. Comparison of Zn and Sr effects on thermal properties and on the excess entropy of doped glasses for use in the biomedical field. Thermochimica Acta 668, 58-64. https://doi.org/10.1016/j.tca.2018.08.008

[16] Oudadesse, H., Dietrich, E., Bui, X.V., Le Gal, Y., Pellen, P., Cathelineau, G., 2011. Enhancement of cells proliferation and control of bioactivity of strontium doped glass. Applied Surface Science 257, 8587-8593. https://doi.org/10.1016/j.apsusc.2011.05.022

[17] Hench, L.L., 1997. Sol-gel materials for bioceramic applications. Current Opinion in Solid State and Materials Science 2, 604-610. https://doi.org/10.1016/S1359-0286(97)80053$\underline{8}$

[18] Itoh, H., Sugimoto, T., 2003. Systematic control of size, shape, structure, and magnetic properties of uniform magnetite and maghemite particles. Journal of Colloid and Interface Science 265, 283-295. https://doi.org/10.1016/S0021-9797(03)00511-3

[19] Hench, L.L., 2000. A Genetic Theory of Bioactive Materials. Key Engineering Materials 192-195, 575-580. https://doi.org/10.4028/www.scientific.net/KEM.192-195.575

[20] Kokubo, T., Kushitani, H., Ohtsuki, C., Sakka, S., Yamamuro, T., 1992. Chemical reaction of bioactive glass and glass-ceramics with a simulated body fluid. Journal of Materials Science: Materials in Medicine 3, 79-83. https://doi.org/10.1007/BF00705272

[21] Zarzycki J., Les verres et l'état vitreux, 1st ed., Masson, Paris, 1982.

[22] Mabouk, M., Mostafa AA., Oudadess, H., Wers, E., Lucas-Girot, A., EL-Gohary, MI., 2016. Comparative Study of Nanobioactive Glass Quaternary System 46S6. Bioceramics Development and Applications 04. https://doi.org/10.4172/2090-5025.1000072

[23] Kay, S., Thapa, A., Haberstroh, K.M., Webster, T.J., 2002. Nanostructured Polymer/Nanophase Ceramic Composites Enhance Osteoblast and Chondrocyte Adhesion. Tissue Engineering 8, 753-761. https://doi.org/10.1089/10763270260424114

[24] Palin, E., Liu, H., Webster, T.J., 2005. Mimicking the nanofeatures of bone increases bone-forming cell adhesion and proliferation. Nanotechnology 16, 1828-1835. https://doi.org/10.1088/0957-4484/16/9/069

[25] Matsuda, T., Davies, J.E., 1987. The in vitro response of osteoblasts to bioactive glass. Biomaterials 8, 275-284. https://doi.org/10.1016/0142-9612(87)90115-3 
[26] Hayman, EG., Pierschbacher, MD., Suzuki, S., Ruoslahti, E., 1985. Vitronectin--a major cell attachment-promoting protein in fetal bovine serum Experimental Cell Research 160, 24558 . 


\section{Caption figures:}

Figure 1: Schema for the synthesis of 46S6

Figure 2: Preparation of the sample's cylinders of glass/wax

Figure 3: DSC thermogram of 46S6

Figure 4: FTIR spectra results of soaked 46S6

Figure 5: DRX diffractogram of each sample from different immersion time

Figure 6: Evolution of concentration of $\mathrm{P}, \mathrm{Si}$ and $\mathrm{Ca}$ in $\mathrm{SBF}$ for different duration of immersion Figure 7: Topography, phase and 3D topography with phase overlay of two weeks after soaking in SBF

Figure 8: Topography, phase and 3D topography with phase overlay of one month after soaking in $\mathrm{SBF}$

Figure 9: Topography, phase and 3D topography with phase overlay of two months after soaking in SBF

Figure 10: Example of 3D photography for 2 months immerged sample 


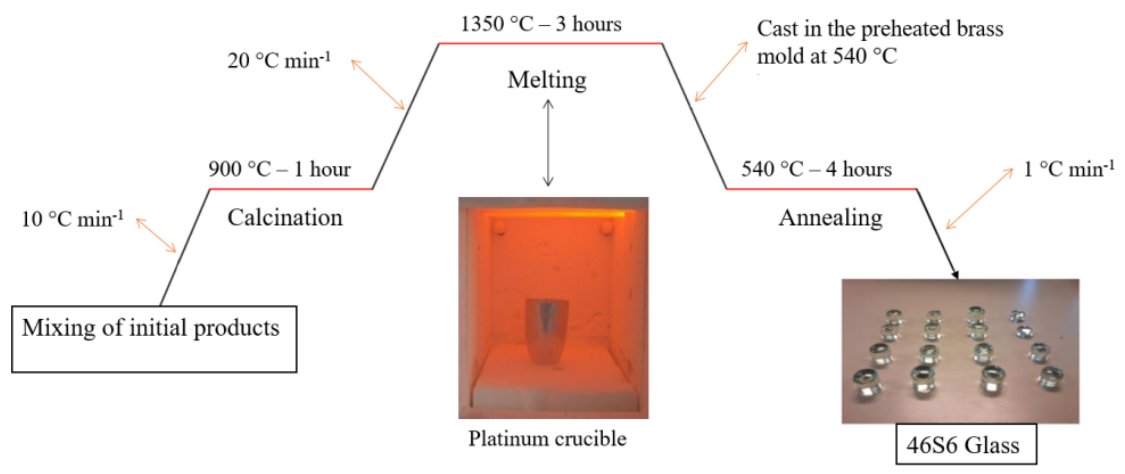




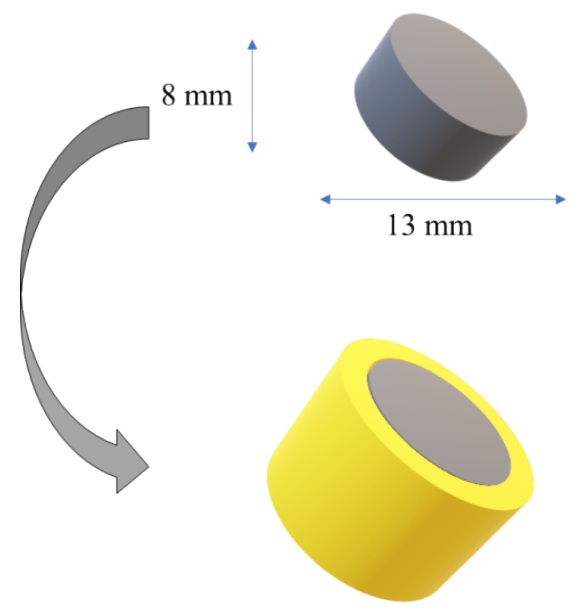

Cylindric samples 


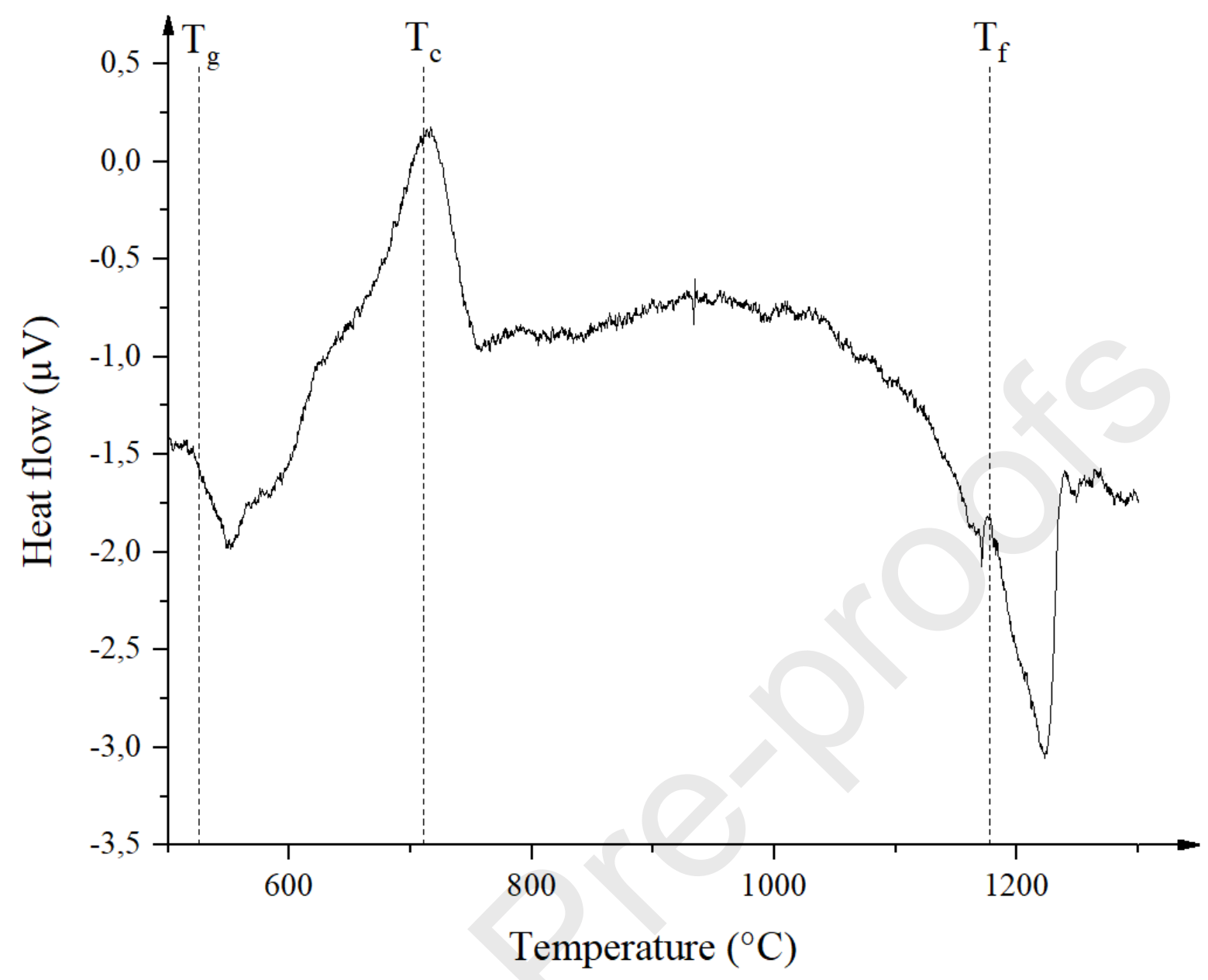




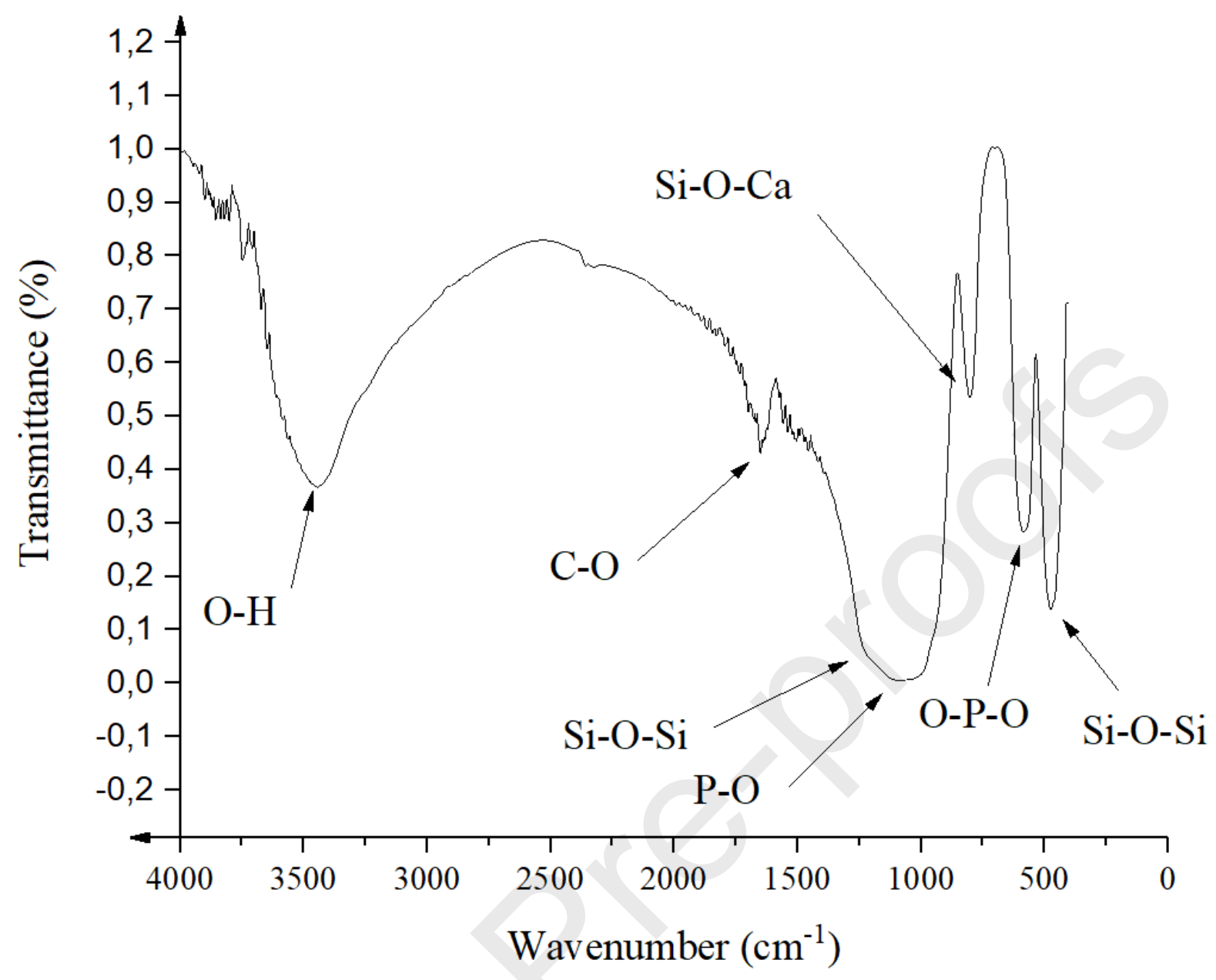




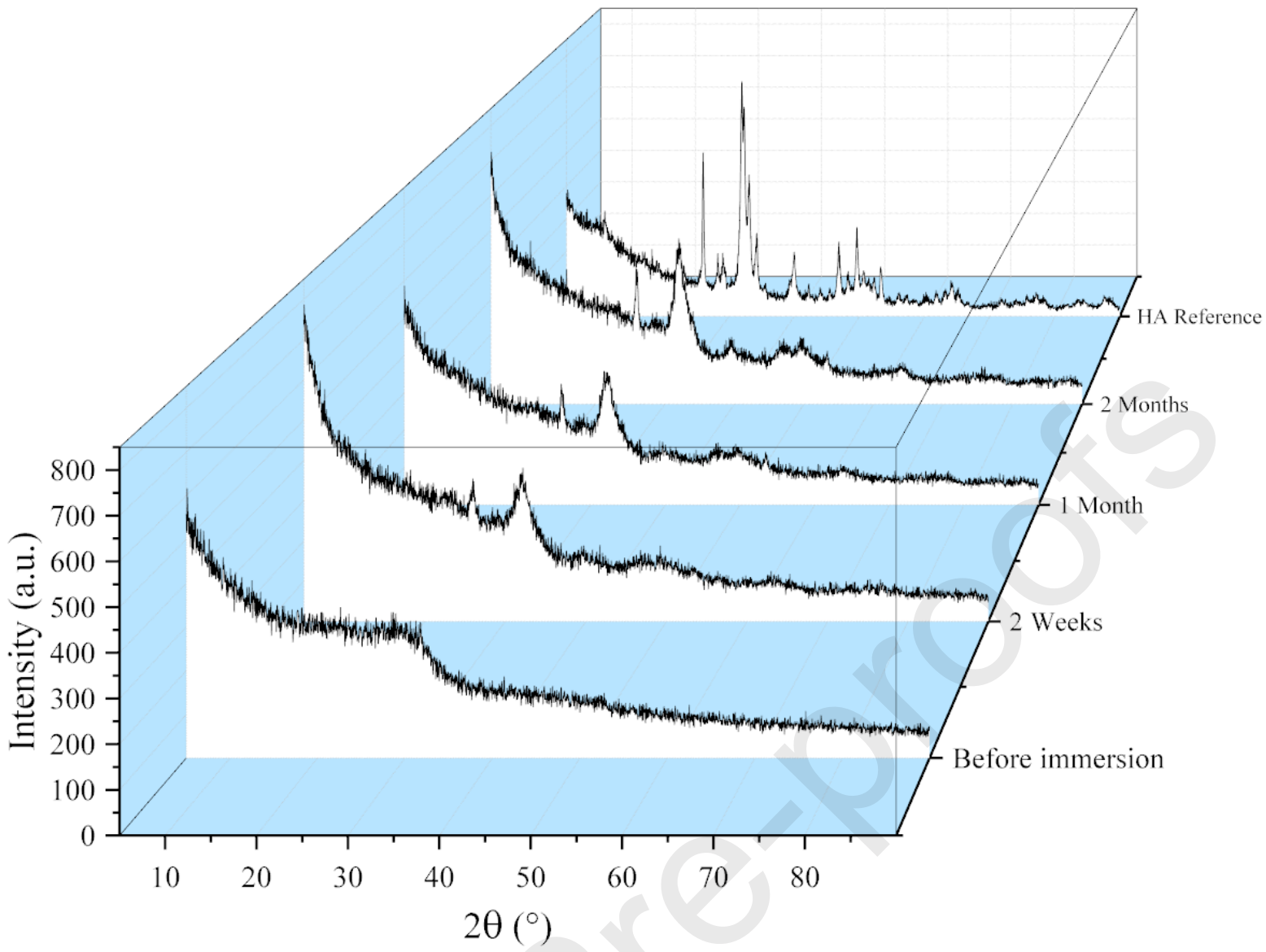




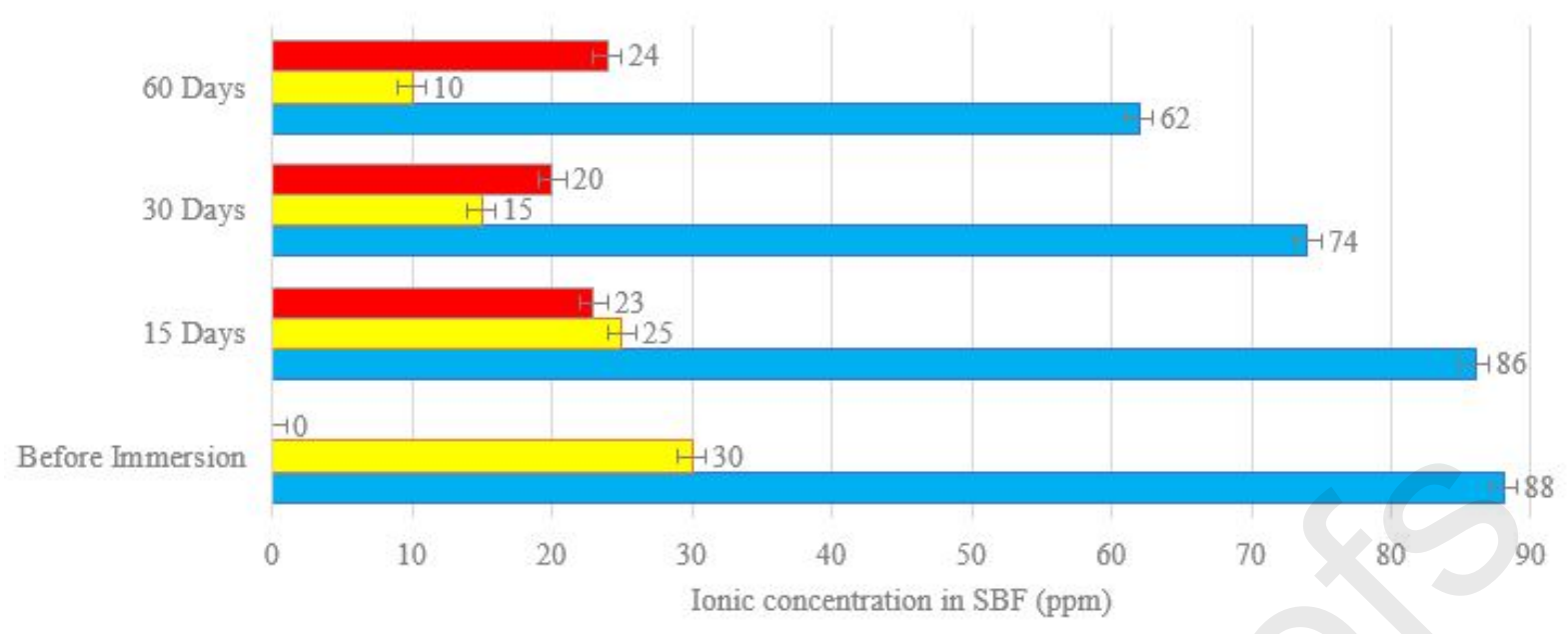

| $[\mathrm{Si}](\mathrm{ppm}) \quad \square[\mathrm{P}](\mathrm{ppm}) \quad \square[\mathrm{Ca}](\mathrm{ppm})$ 


\section{Journal Pre-proofs}
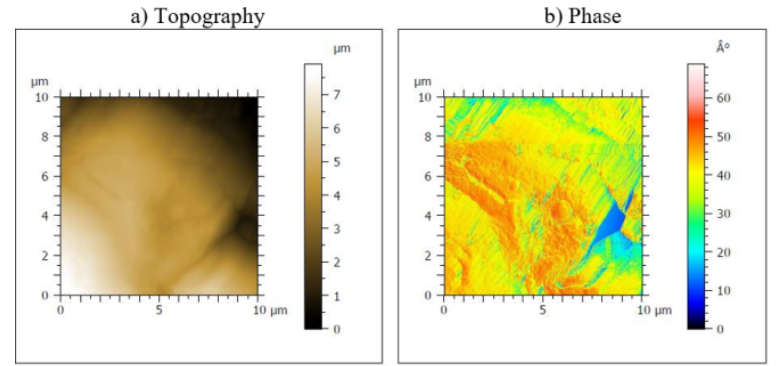

c) 3D-Topography with phase

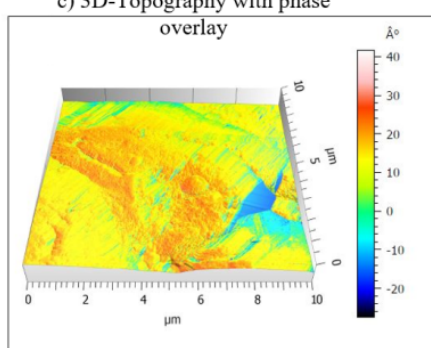




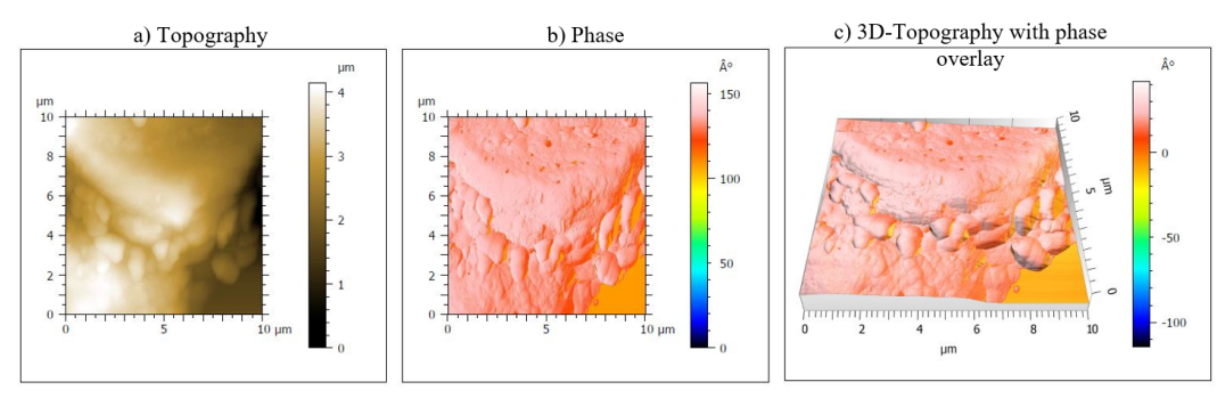




\section{Journal Pre-proofs}

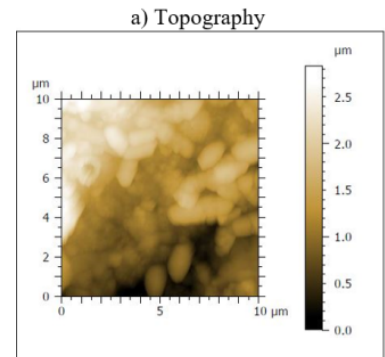

b) Phase

c) 3D-Topography with phase

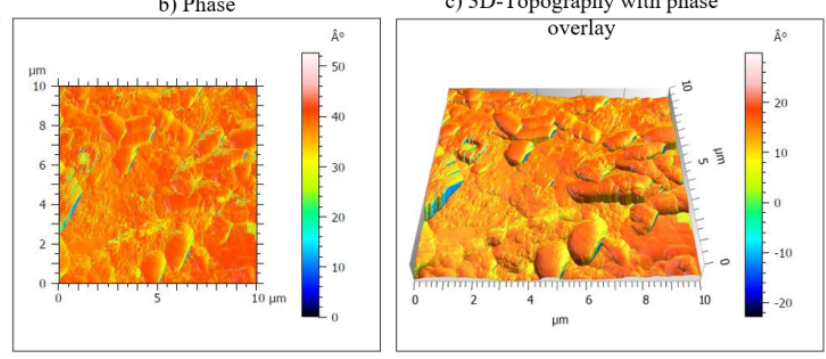




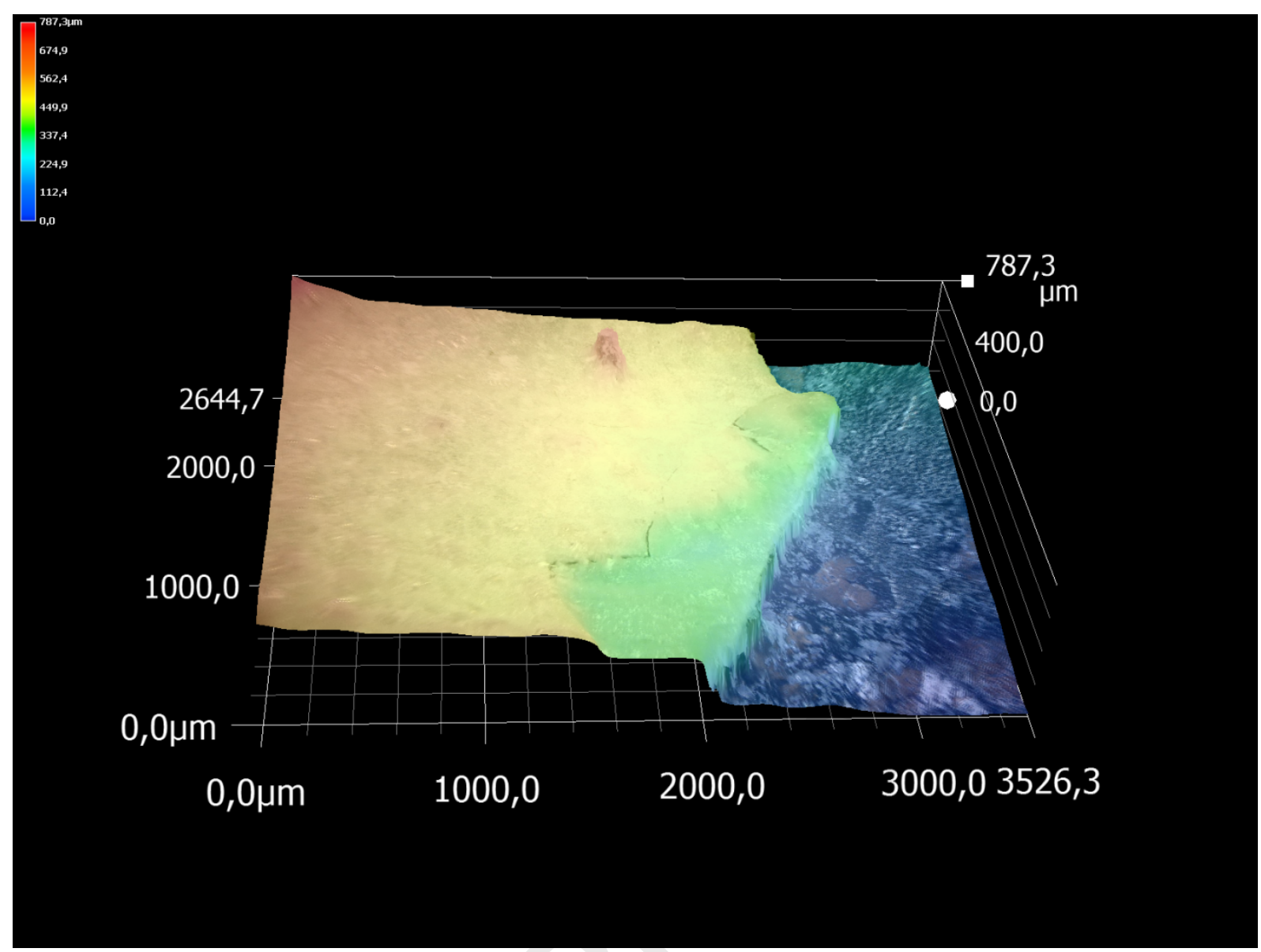


Fine analyses of interactions mechanism of bioactive glass surface after soaking in SBF solution: AFM and ICP-OES investigations

Nicolas Rocton a , Hassane Oudadesse a, Bertrand Lefeuvre a, Henrik Peisker ${ }^{\mathrm{b}}$, Khalid Rbii ${ }^{\mathrm{b}}$

${ }^{a}$ Univ Rennes, CNRS, ISCR-UMR 6226, F-35000 Rennes, France

${ }^{b}$ Nanosurf GmbH , Rheinstrasse 5, 63225 Langen, Germany

Corresponding author: Prof. Dr. Hassane Oudadesse

E-mail: hassane.oudadesse@univ-rennes1.fr

\section{Highlights}

- Increases of glass surface crystallisation with adapted ionic exchanges kinetic.

- State of glass surface at different periods was highlighted using AFM analyses.

- Surface homogenization over time, the gap decreases in phase from 60 to $15 \AA$.

- Surface roughness decreasing over time, the gap decreases in height from 7 to $3 \mu \mathrm{m}$. 